\title{
The downside of transparent physician payments: public distrust of the entire profession
}

Cite as: CMAJ 2019 May 27;191:E589-90. doi: 10.1503/cmaj.109-5754

Posted on cmajnews.com on May 7, 2019.

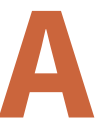

merican patients trust their doctors less than they did five years ago. One contributing factor, according to a recent study, could be disclosure of payments from pharmaceutical and medical device companies to physicians. "Public disclosure of payments was associated with lower trust in one's own physician regardless of whether respondents knew their physicians had received payments," the authors concluded.

Genevieve Kanter, an economist at the University of Pennsylvania and lead author of the study, published in JAMA Network Open, attributes this mistrust to concerns over conflicts of interest that industry ties tend to evoke. Although health insurance claims are less controversial than industry payments, some Ontario doctors are worried the disclosure of billing information for individual physicians could also lead to public confusion and mistrust.

Since 2014, the Toronto Star has been trying to access the names and billing information of Ontario's 100 highest claiming doctors. The Ontario Medical Association (OMA) has spent years attempting to keep this information private. But following a recent decision by the Supreme Court of Canada, the Ministry of Health and Long-Term Care must now release it.

Dr. Nadia Alam, president of the OMA, said that although the medical association respects the decision of the courts, disclosure can have unintended consequences. "Many of us are concerned that any context of how physician billing actually works will be lost against headlines focusing on a handful of physicians at the top of the list," Alam said.

That even American physicians who did not accept industry payments took a reputational blow might suggest there's reason to be worried. In the United States, the Physician Payments Sunshine Act required that industry payments be

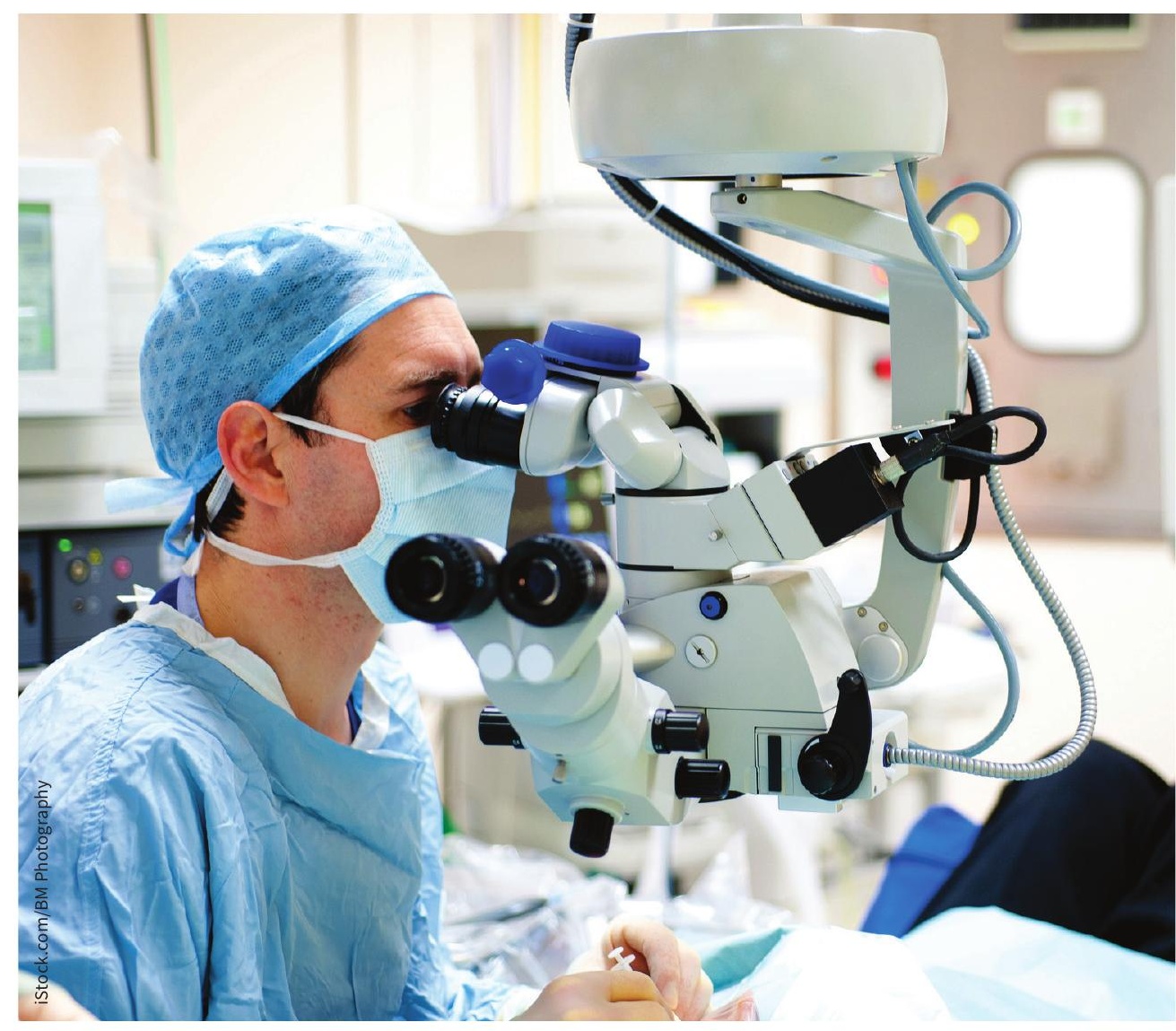

Many of the top-billing physicians in Canada are ophthalmologists. made public in 2010. Even though less than $5 \%$ of US adults have accessed the data, Kanter suggests the information still made its way into the public eye. She attributes this to an unlikely source: the comedian John Oliver.

In 2015, Oliver tackled pharmaceutical marketing to doctors on his television program. In a segment that has since attracted more than 10 million views on 
YouTube, he encouraged viewers to look up their doctors' industry ties, perhaps exemplifying what has been called the "John Oliver Effect" on public policy.

When it comes to billing information, it's "very important that this disclosure is done in a way that makes sense," said Alam. This means explaining that physician billing doesn't translate directly to income. Instead, 30\% of billings, on average, are spent covering costs such as office space, medical equipment and staff salaries. Overhead can sometimes be as high as $50 \%$.

According to Kanter, practice structures can lead to higher billing. For example, some doctors bill on behalf of nurse practitioners or other clinicians. Higher case volume or sicker patient populations could also play a role. As well, practices might be represented unevenly depending on whether they bill through fee-forservice or capitation. "Without that context, I think it is hard to interpret what actually will be disclosed," said Kanter.

In British Columbia, Manitoba and New Brunswick, physician billing data have been public for decades. In the United States, Medicare has released physician billing information since 2014; Kanter said she isn't aware of any effect that has had on trust in physicians in the US.

Brian Beamish, the information and privacy commissioner of Ontario, said his office was pleased with the court's decision for billings disclosure in Ontario, which falls in line with growing expectations of transparency when it comes to public funds. "Ontarians have the right to scrutinize government spending and decision-making," he said.

The Toronto Star has reported that physician compensation makes up roughly $20 \%$ of the provincial budget more than $\$ 12$ billion. According to previously released data, the top 100 billers, mostly ophthalmologists and radiologists, claimed a combined \$191 million in 201213. The highest biller took in $\$ 6$ million.

Caroline Mercer, Toronto, Ont. 